\title{
Seismic resistance of multi-storey reinforced concrete wall-frame structures at destructive earthquakes
}

\author{
Baisbay T. Yerimbetov, Berik M. Chalabayev, Yairakhan B. Kunanbayeva, Zhenisbek A. Ussenkulov, \\ Zhenis I. Orazbayev, Zhumadilla A. Aldiyarov \\ ${ }^{1}$ Department of Industrial, Civil and Road Construction, M. Auezov South Kazakhstan State University
}

\begin{abstract}
This article shows results of a numerical study of the behavior of multi-storey reinforced concrete wall-frame structure under loads of special combination, considering seismic impact that corresponds to destructive earthquake. The purpose of the study is to identify conditions that increase energy absorption capacity of wall-frame structure under the effect of destructive earthquakes as well as methods for assessing the energy absorption capacity of wallframe structure at the design stage. Numerical studies were carried on 9-storey frame building, designed for construction in the area with an estimated seismicity of 7 points. Loads of special combination were applied until the complete exhaustion of the bearing capacity of the structure. The calculations were made using the LIRA software package. Performed studies made it possible to identify and assess bearing capacity margin of buildings designed to meet the requirements of valid antiseismic construction regulations if earthquake intensity exceeds the design calculated value. As a result of a numerical study of the work of a 9-storey frame reinforced concrete building of a frame scheme corresponding to the third version of the system, the building withstood the load exceeding the estimated norm by $30 \%$. The value of the coefficient showing the deformation properties during operation of the system at loads exceeding the calculated values before failure, amounted to $\mathrm{K}=3.1$. The results obtained give the designer the opportunity to create conditions for the appearance of plastic joints in as many cross sections of frame elements as possible. This in turn leads to an increase in the energy intensity of the skeleton, capable of absorbing the excess energy of a destructive earthquake. We have developed the recommendations for determining bearing capacity margin of buildings at design stage if earthquake intensity exceeds calculated value.
\end{abstract}

\begin{tabular}{ll}
\hline Keywords: & Multi-storey framed buildings, Seismic impacts, Loads of a special combination, \\
& Energy absorption capacity of the system, Bearing capacity margin. \\
\hline
\end{tabular}

\section{Corresponding Author:}

Yairakhan B. Kunanbayeva,

Department of Industrial, Civil and Road Construction,

M. Auezov South Kazakhstan State University,

160012, 5 Tauke Khan Ave., Shymkent, Republic of Kazakhstan.

E-mail: ya.kunanbayeva@murdoch.in

\section{Introduction}

For the purpose of this article, destructive earthquakes are earthquakes, which intensity exceeds calculated values established by valid regulations by 1-2 points. The intensity of the earthquake in this case was estimated in points according to the MSK-64 (K) scale.

As a rule, such earthquakes cause significant damage to the supporting buildings and structures or result in their complete destruction. Destructive earthquakes are quite frequent phenomenon, causing significant material damage and leading to numerous human victims. Therefore, it is critical to study the behavior of 
structural elements of buildings and structures during such earthquakes, as well as develop of measures aimed at mitigation of their negative effects.

Structural layout that is most frequently used in seismic areas is multi-storey reinforced concrete wall-frame structures. Such structures are characterized by multiple static indeterminacy and therefore should have certain bearing capacity margin. Strength margins of the frame elements are especially critical for buildings designed in seismic areas since seismic impact may exceed calculated value established by valid normative documents during earthquake.

We believe that the increased bearing capacity of a multiple statically indeterminate frame system is due to its increased energy absorption capacity, i.e. the ability of the system to absorb excessive energy. This can be explained by the fact that plastic hinges may appear in sections of system elements where forces from external impacts exceed critical force taken by them.

In this case, the forces are redistributed between overloaded or lightly loaded sections of elements of frame structure. Due to this fact, the system may take additional external impacts. Theoretically, such frame system designed for seismic areas should have high energy absorption capacity for unexpected exceeding of earthquake intensity stipulated by the project.

Reinforced concrete wall-frame structures were not always able to absorb excessive seismic energy judging from the experience of destructive earthquakes. In most cases, basic supporting elements of such systems are subject to brittle destruction without plastic hinges, due to which the forces are not redistributed between sections of system elements.

It is known that plastic hinge takes place in reinforced concrete structure only if the tension in tensioned reinforcement reaches yield point, and the concrete of the compression area does not lose the bearing capacity. Such system should absorb excessive seismic energy in the event of destructive earthquakes. However, it is necessary to create certain conditions that promote the development of plastic hinges in the largest possible number of elements of the frame system.

In spite of ensuring seismic resistance of buildings according to design value of earthquake intensity, one of the major tasks in antiseismic construction is the development of methods for calculation of buildings that would allow precise evaluation of structure's ability to resist destructive seismic impacts when the intensity of an earthquake exceeds the design value. Therefore, it is necessary to study the behavior of structure elements under destructive seismic force.

Such studies will make it possible to develop recommendations for determining system's bearing capacity margin for destructive earthquake at design stage. This study also includes the study of the behavior of buildings and structures under loads, exceeding the limit values established by the current standards. Today, such studies can be carried out with the use of numerical methods and software that considers real properties of structure materials under the effect of destructive loads. This makes it possible to analyze the behavior of structures with different stiffness properties within entire range of strength properties of materials, including destruction point.

The purpose of our study is to identify conditions that are necessary for the formation of plastic hinges in sections of the elements of reinforced concrete wall-frame structures. The fulfillment of these conditions even at the design stage can lead to the increase in the energy intensity of frame systems due to redistribution of forces from overloaded sections to light loaded sections.

Analysis of results of studies in the field of antiseismic construction [1-12] showed that works devoted to increase in energy absorption capacity of the structures are almost absent. Since studies [1-12] provided only general guidelines for the construction of earthquake-resistant frame buildings, in this study, the authors focus on increasing the energy intensity of buildings, which significantly distinguishes this article from the above. Therefore, our study can be of interest not only from a practical, but also from a scientific point of view.

In this work, authors studied the issues of increasing the bearing capacity of reinforced concrete frame-wall structures due to the formation of the greatest possible number of plastic hinges from external impacts exceeding the calculated values that can occur at destructive earthquakes. 


\section{Theoretical overview}

Analysis of the effects of destructive earthquakes on the basis of surveys of the results of destructive earthquakes suggests that the destruction in elements of framed systems of destroyed buildings has brittle nature [1]. This type of destruction prevents plastic hinges and redistribution of forces between overloaded and light loaded sections of framed system elements. The work [1] covers the results of a survey of frame and panel buildings after the earthquake in Spitak city (December 7, 1988 in the northern regions of Armenia) and the earthquake in the Southern Kuril Islands (October 4, 1994). Damage and destruction of buildings and structures were analyzed during these destructive earthquakes. There are examples showing that such earthquakes can cause complete destruction of the building frame.

According to $[1,2]$, the intensity of seismic impact exceeded the level established by standards that were valid at the time of the earthquake by the following values:

- in Spitak city: by 2 points,

- in Kirovakan and Stepanavan city: by 1 point,

- in Leninakan city: by $0.5 \ldots 1.0$ points.

According to our terminology, all of these earthquakes refer to destructive earthquakes.

The results of the engineering analysis of the consequences of the earthquake that occurred in Armenia in $1988[1,2]$ showed that the reinforced concrete wall-frame structures did not have sufficient bearing capacity margin. Therefore they were seriously damaged and even destructed completely.

Some authors in their work [6-12] indicate that one of the reasons for the insufficient seismic resistance of the supporting structures of multi-story reinforced concrete wall-frame buildings is that such buildings are designed for unreasonably underestimated seismic loads. They came to the conclusion that the value of seismic loads in regulations $[4,5]$ is unreasonably underestimated.

It should be noted that at current methods for assessing the seismic resistance of wall-frame buildings consider elastic-plastic behavior of building elements, taking into account the effect of the peak values of the seismic impact level [13-29]. The value of residual system deformation that takes place under the effect of peak values of seismic impact level is used for evaluation of seismic effect. The estimation of seismic resistance by the value of residual deformations considers not only the elastic-plastic properties of the system but also the effect of the levels of seismic impact.

However, this method for estimating seismic resistance makes it impossible to determine the energy intensity of the system at the design stage of buildings and structures and does reveal the behavior of buildings and structures under destructive earthquakes. In certain cases, such earthquakes are the cause of the complete destruction of the elements of reinforced concrete structures.

The design of buildings and structures planned for construction in seismic areas consider requirements of regulations of the relevant countries.

At the same time, the degree of ensuring the seismic resistance of designed buildings and structures depends on the extent, to which regulations of the relevant countries reflect the results of theoretical and experimental studies of structures and buildings in the field of antiseismic construction. One of the major requirements to seismic resistance of a structure is the development of plastic deformations in structures and junctions, the need to provide constructive measures that ensure the stability of geometric shape of structural systems, as well as eliminating the brittle destruction of their elements during the development of such deformations.

Today, regulations on design of buildings and structures adopted in different countries provide for the development of plastic deformations in structural elements and the possibility of eliminating brittle damages. Moreover, the evaluation of favorable effect of the development of plastic deformations on seismic resistance of reinforced concrete elements of wall-frame buildings varies depending on the country.

For example, according SNiP II-7-81* and SP 14.13330.2011, the favorable effect of the development of plastic deformations on the bearing capacity of reinforced concrete structures under seismic impact is partially based on structure behavior factor $m_{k p}$, that is equal to 1.2 upon calculation of the strength by normal sections 
of reinforced concrete elements fitted with reinforcement that have physical yield strength. The disadvantage of this approach is based on the fact that the use of this factor prevents plastic deformations in sections of reinforced concrete elements under seismic impact that exceeds design value.

Instead of factor $m_{k p}$, Construction Codes and Regulations of Republic of Kazakhstan, namely SNiP RK [4], provide for the use of two factors: reinforcement behavior factor $\gamma_{s i}$ and concrete behavior factor $\gamma_{b i}$, which consider the development of plastic deformations in reinforcement and damage accumulation in concrete, respectively. However, judging from the results of the study of behavior of wall-frame buildings under seismic impact, the use of above-mentioned factors doesn't allow control of formation of plastic areas in the elements of wall-frame systems under the effect of destructive earthquakes. Judging from the result of analysis of earthquake consequences, destructive earthquakes with intensity that exceeds designed value by 1 and 2 points are quite often. Under these circumstances, it is necessary to regulate the order of formation of plastic areas in the elements of statically indeterminate systems, which include wall-frame structures, in order to improve the seismic resistance of such buildings in general under destructive earthquakes while preventing destruction of more critical structures that lead to complete destruction of the buildings.

Regulations adopted in non-CIS countries [11] provide for different specifics of the impact as well as elasticplastic properties of materials of structures, partially considering additional structure behavior factors that are considered together with conditions in structural elements or thresholds of their static bearing capacity. USA regulations provide for the use of such factors in order to consider elastic-plastic properties of material and specifics of behavior of some connections. Their values are taken from $0^{0}$ for bonds tensioned perpendicular to horizontal joints to $1.0^{0}$ for monolithic reinforced concrete structures and joints of reinforced concrete elements are calculated on the basis of factor that is equal to 0.5-0.8. According to regulations of New Zealand, structure behavior factor is taken from 0.8 to 2.5. In Argentina, the same factor is equal to 1.4. Regulations of some other countries contain recommendations for increasing the permissible stresses by 20$35 \%$ in comparison with calculated stresses under conventional bearing loads [11]. Considering abovementioned facts, the consideration of specifics of seismic effect and elastic-plastic properties of materials is compulsory and these factors are considered differently, depending on the country.

The analysis of the requirements of European construction standards (Eurocodes) [30] shows that the norms of European countries also take into account the ability of different structural systems to resist seismic impact in terms of nonlinear deformation. This circumstance in Eurocodes is considered by behavior factor $q$ used for determining the value of seismic loads. Behavior factor $\mathrm{q}$ is a factor used to reduce seismic forces, determined though linear calculation, in order to take into account the nonlinear response of the structure, conditioned by nonlinear behavior of the material, the structural system and features of the adopted design methodology. Behavior factor is an approximate value of the ratio between seismic loads that would affect building or structure with its fully elastic response and 5\% viscous damping and seismic loads that can be used in the design based on the results of linear elastic calculation. The values of behavior factor determine the ability of structural systems to resist seismic impacts in terms of nonlinear deformation and determine extend of consideration for their nonlinear behavior under seismic impacts.

The values of the coefficient $K_{2}$ established by regulations of the Russian Federation, as well as other similar coefficients adopted in other CIS-countries consider the reduction of seismic load due to the development of inelastic deformations in the systems, depending on the adopted design solutions. In terms of value, these coefficients adopted by regulations of CIS-countries, including regulations of the Russian Federation and the Republic of Kazakhstan, correspond to the inverse value of behavior factor $(1 / q)$ adopted by Eurocodes when determining the value of the seismic load. In terms of physical meaning, coefficients used in CIS countries and in Eurocodes take into account the possibility of reducing the value of the seismic load due to the development of inelastic deformations depending on the adopted design solutions of the designed buildings. At the same time, the approaches adopted in regulations of these countries make it possible to determine the degree of reduction of seismic load on buildings in the process of development of plastic deformations, 
depending on adopted design decisions. At design stage, it is impossible to give certain answer to the question whether the degree of development of plastic deformations corresponds to the level of reduction of seismic loads stipulated by the project [31-33].

The analysis of previous studies and regulatory documents in many countries has shown that there is no methodology allowing estimation of system's ability to absorb excess energy during destructive earthquakes even at the design stage. There are no developed recommendations for the calculation of buildings and structures, which would allow even at the design stage to evaluate the ability of structures to resist earthquakes, the intensity of which exceeds the values considered in calculations at design stage. The abovementioned coefficients adopted by regulations of seismic resistant construction in many countries, considering the different levels of seismic load reduction depending on the adopted design layouts, do not always justify the increase in energy intensity of the system.

Judging from analysis of the consequences of destructive earthquakes, the latter can cause significant damage to the frame elements or their complete destruction, regardless of the degree of development of plastic deformations, which is adopted during the design of the building. In such cases, the reinforced concrete frame will not be able to fully realize its reserves, determined during the design of systems. Reinforced concrete frame can redistribute the force from overloaded sections to less loaded ones only when plastic deformations, namely the formation of plastic hinges, can appear in any section of frame elements.

\section{Material and methods}

This work was based on numerical studies that allowed studying the behavior of all structural elements of a building in the entire range of strength properties of concrete and reinforcement, including the moment of destruction. This research method was chosen due to fact that it allows to set different variants of stiffness characteristics of its elements. Adopted methods of research allow us to set any quantity of loading steps before destruction and under any combination of loads. Moreover, you can get data about behavior of all elements of building frame at any stage of construction.

Study program provided for study of the behavior of reinforced concrete multi-storey frame buildings under seismic loads and destructive values in order to identify the bearing capacity of such systems if earthquake intensity exceeds its estimated values, established by standards for this region. For this purpose, the program includes studies of the behavior of 9-storey wall-frame building, designed for construction in the area with an estimated seismicity of 7 points under combined effect of loads of a special combination up to the complete exhaustion of the bearing capacity.

In this case, three variants of buildings with different stiffness characteristics of columns along the height of a building were subjected to numerical studies. In the first variant, the characteristics of a multi-storey frame building are adopted as follows:

- number of floors: 9;

- the height of ground floor: $3.8 \mathrm{~m}$;

- the height of other floors: $3 \mathrm{~m}$;

- cross-section dimensions of the bolt $40 \times 60 \mathrm{~cm}$;

- the thickness of the monolithic plate: $20 \mathrm{~cm}$;

- cross-sectional dimensions of columns for all floors of the building: $40 \times 40 \mathrm{~cm}$;

- concrete grade B25;

- longitudinal reinforcement class A-III.

A preliminary design of building for loads of a special combination with an earthquake intensity of 7 points showed that the percentage of reinforcement of columns on the 1 st floor exceeded $7 \%$, which is unacceptable for seismic areas according to regulations of many countries of the world. Therefore, in the first variant of the building, the cross sections of the ground floor columns were increased to $45 \times 45 \mathrm{~cm}$ so that reinforcement percentage of the columns did not exceed 6\%, which is maximum allowable value for seismic areas adopted by many countries of the world. Other parameters of the building remain the same. 
In the second variant of the 9-storey building, the cross-sectional dimensions of the columns were adopted so that the amount of longitudinal reinforcement required to ensure the seismic resistance of the building did not exceed 3\%. At the same time, the condition of minimum reinforcement of columns was observed in accordance with the design requirements of the SNiP RK [4]. This condition was ensured by increase of crosssectional dimensions of the columns. The cross-sectional dimensions of the columns from the first to the fourth floors of the building have been increased to $50 \times 50 \mathrm{~cm}$, and the cross-sectional dimensions of the columns from the fifth to the ninth floors of the building have been increase to $40 \times 40 \mathrm{~cm}$. This measure allowed us to reduce relative height of the compressed concrete zones in the cross sections of the columns and create the conditions for reaching yield stress, namely preconditions for the development of plastic deformations (the appearance of plastic hinges) in the tensioned reinforcement.

We have also studies the behavior third variant wall-frame structure where cross-sectional dimensions of the columns are adopted in order to ensure normal level of compression by longitudinal force. At the same time, the dimensions of the cross sections of the columns were adopted in such a way that the number of longitudinal reinforcement of the columns was adopted to be close to the minimum permissible percentage of reinforcement of the columns in accordance with the requirements of antiseismic construction standards [4].

The compliance with these requirements made it possible to create favorable conditions for development of plastic deformations in eccentrically loaded buildings under loads of a special combination, considering the seismic effects. Considering accepted cross-sectional dimensions of the columns, the amount of reinforcement should be close to the minimum percentage of reinforcing.

Considering the above conditions, the dimensions of the cross section of the columns should be as follows: for ground and second floors: $55 \times 55 \mathrm{~cm}$, for the third and fourth floors: $50 \times 50 \mathrm{~cm}$, for the fifth and sixth floors: $45 \times 45 \mathrm{~cm}$, for seventh to ninth floor: $40 \mathrm{x} 40 \mathrm{~cm}$.

All three variants of buildings were subjected to seismic calculations with an earthquake intensity of 7 points, in order to determine the number of reinforcement in reinforced concrete frame elements.

Frame structure was designed by LIRA software package based on combinations of loads, considering the seismic impact. The frame was loaded in steps, corresponding to $10 \%$ of standardized loads of special combination with an earthquake intensity of 7 points. In other words, the 10th loading step corresponds to the loads of particular combination with an earthquake intensity of 7 points. Each loading step was accompanied by horizontal movements of the building caused by elastic-plastic deformations of concrete and reinforcement. The following dependences were created: 'Horizontal load - horizontal displacement'. The behavior of reinforced concrete structure was simulated by exponential dependence 'tension-deformation' that was based on real values of strength and stress-strain behavior of concrete of grade B25 under compression and tension forces. The behavior of longitudinal working reinforcement was simulated by the symmetric dependence "tension-deformation" considering the real values of the strength and stress-strain behavior of reinforcement of class A-III under compression and tension forces.

In order to determine the bearing capacity of the building, designed to meet the requirements of the standards of antiseismic construction, its frame system was subjected to seismic impact with intensity exceeding 7 points. The effect of destructive earthquakes was simulated in order to determine the exceeded seismic load.

This method for studying the behavior of frame buildings made it possible to reveal the ability of the studied systems to absorb excess seismic energy, the accommodation of which is not calculated at design stage. In order to study the ability of systems to absorb excess seismic energy, the elastic-plastic work of the system elements, and the system as a whole, was studied until complete destruction. Evaluation of the ability of structural elements of the frame to absorb seismic energy was carried out using energy criteria.

In our studies, the ability of the system to deform at seismic loads exceeding the design value is estimated by the deformation coefficient $\mathrm{K}$. This coefficient is the ratio between total deformation corresponding to the destruction of the system and system deformation corresponding to the design load. Consequently, the coefficient $K$ can be used to assess the system's ability to develop plastic deformations and absorb excess seismic energy under destructive dynamic loads. The higher the value of this coefficient, the greater is the 
energy absorption of the system and its ability to resist the horizontal components of the seismic load that exceeds standard values.

\section{Results and discussion}

The calculations showed that the values of the maximum displacements and wrapping of the floors as a result of the elastic calculation of the reinforced concrete frame structure in all three variants, with the accepted characteristics of its elements, did not exceed the limiting values stipulated by the regulations.

Based on calculation of resistance of reinforced concrete frame systems to special combinations of loads with seismic intensity equal to 7 points pursuant to requirements of SNiP RK [4], it is decided to reinforce elements of reinforce concrete frame with longitudinal and transversal reinforcement. Final reinforcement of the elements of wall-frame building, namely columns, is adopted based o unification of frame elements.

The percentage of longitudinal reinforcement of columns was within $0.88-4.52 \%$ provided that requirements to minimum and maximum percentage of reinforcement are observed. Frame system with such reinforcement was subject to numerical study on the effects of loads of a particular combination, considering the seismic effects of varying intensity, exceeding the calculated values adopted in the design of these buildings.

Figure 1 shows a graph of the horizontal displacement of the building frame at the level of the building coverage under the effect of seismic load, corresponding to the earthquake intensity of 7 points.

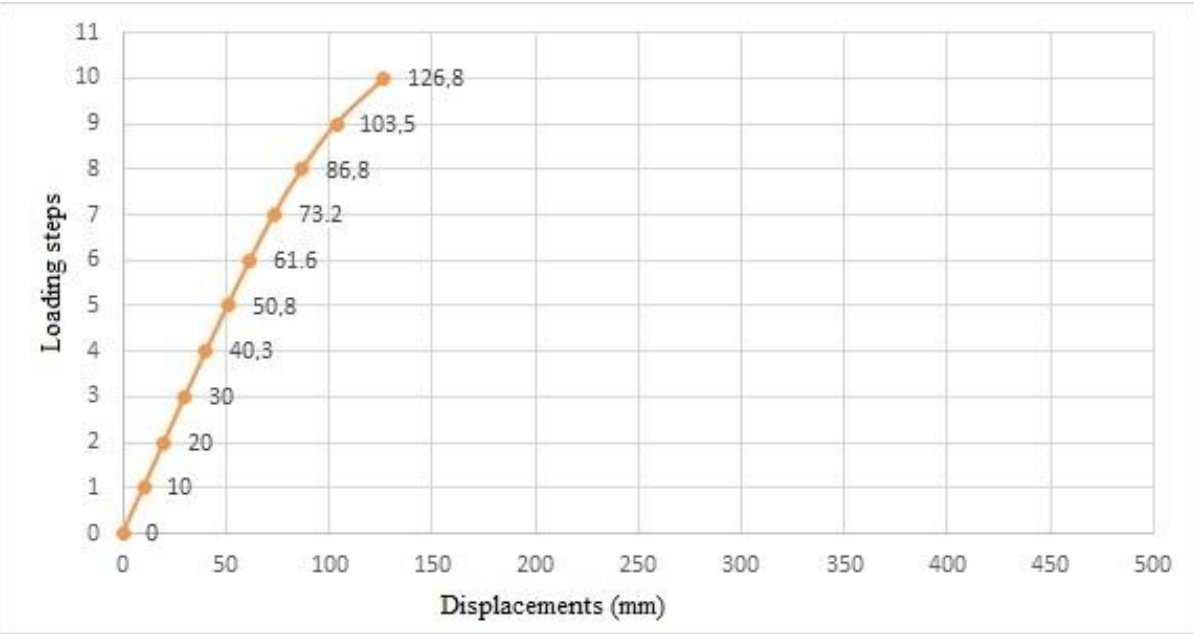

Figure 1. "Load-displacement" dependence for a 9-storey reinforced concrete frame structure for an area with seismic intensity of up to 7 points. Note: The 10th step of loading corresponds to the magnitude of the seismic impact intensity of 7 points

Elastic-plastic behavior of the frame was observed in the process of loading the frame with loads of a special combination, considering the horizontal effects simulating the seismic load of the calculated value. The complete destruction of the frame was achieved in the process of increasing the value of horizontal loads.

An analysis of the stress-strain state of the frame elements showed that, with an increase in the magnitude of the horizontal loads to the complete destruction of the system, there was a complete destruction of the building as a result of the destruction of most loaded columns of the lower floors of the frame. Figure 2 shows the dependence 'horizontal load - horizontal displacement' of the first variant of the system adopted in study. 


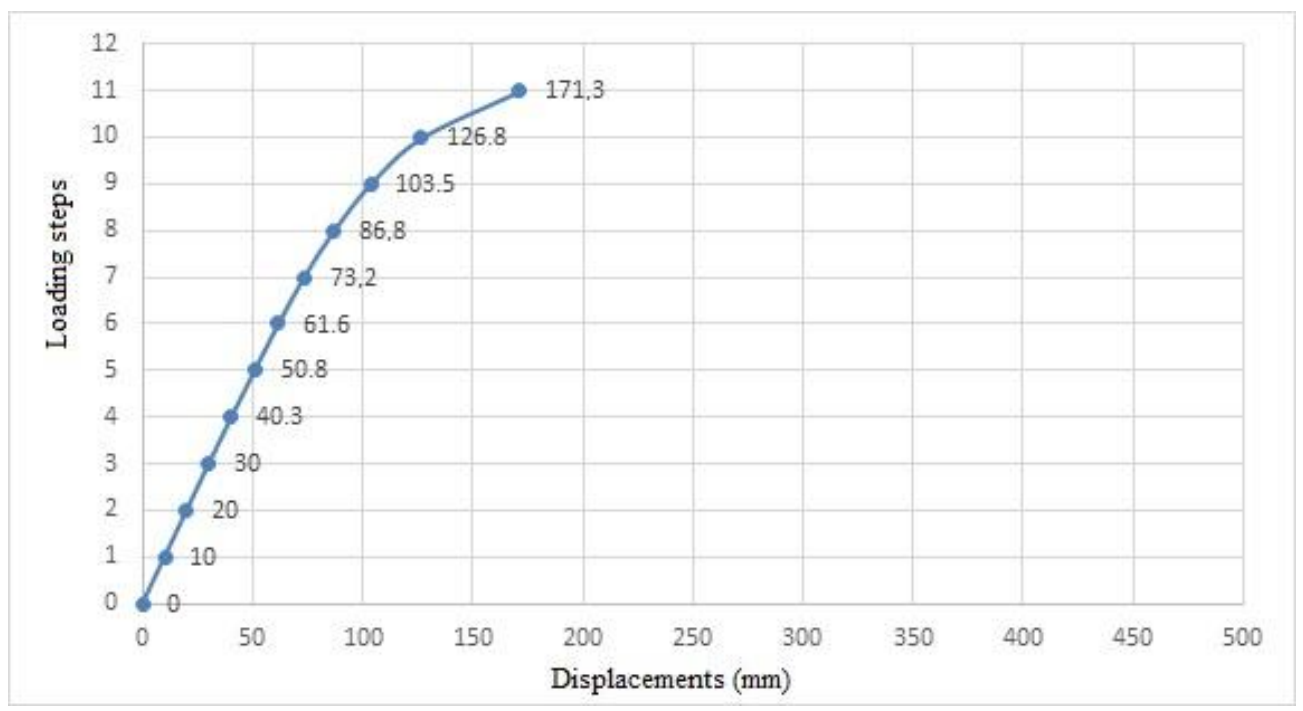

Figure. 2. Dependence "horizontal load - horizontal displacement" for the first variant of wall-frame building;

Note: The 10th loading step corresponds to the magnitude of the seismic impact intensity of 7 points

Considering loads of a special combination corresponding to the design values, the most stressed elements of the frame were the columns of the lower floors of the frame. Based on results of the study of behavior of multi-storey frame under loads of special combinations, considering horizontal loads that simulate seismic effect with an intensity of 7 points, the development of considerable plastic deformations associated with behavior of the reinforcement in flow range or outside it was not observed. When values of seismic force reach design level stipulated by regulations, in sections of columns of higher floors, the deformations in concrete and reinforcement were considerably lower than their threshold values.

Figure 3 shows the results of study of the stress-strain state of the frame elements considering the elasticplastic behavior of reinforced concrete materials.

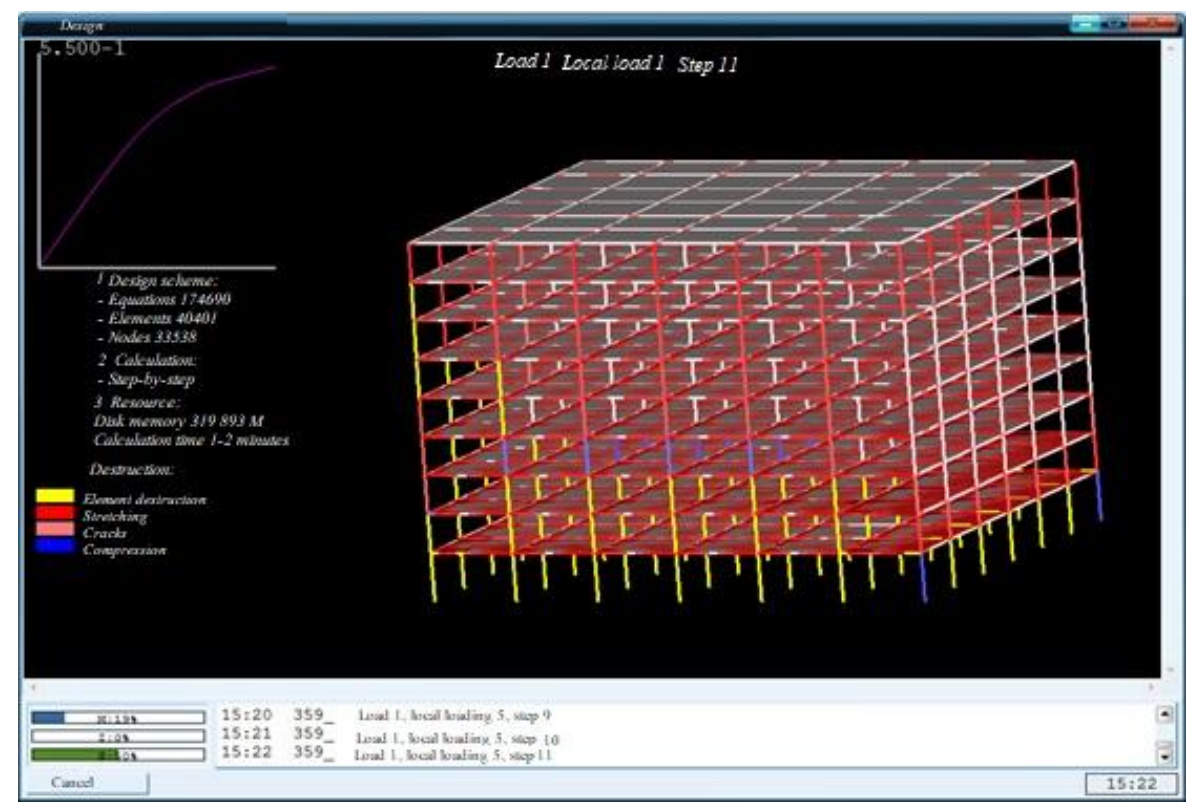

Figure 3. Frame condition corresponding to destruction (11th loading step with horizontal load)

This figure shows that loss of bearing capacity of most of the columns of three lower floors is mainly conditioned by destruction of the building as a whole ( $96 \%$ of the ground floor columns, $86 \%$ of the second floor columns and $82 \%$ of the third floor columns). Judging from this example, it is impossible to create the 
system where the development of considerable plastic deformations would take place before destruction due to behavior of reinforcement in plastic areas.

Judging from the results of this numerical study, frame buildings are subject to destruction under the effect strong destructive horizontal loads simulating seismic loads due to destruction of lower floor columns that are subject to the highest longitudinal compressive force under development of considerable plastic deformations in general. Moreover, bearing capacity of the most columns of upper floors fails to reach its threshold value before destruction.

At the time of complete destruction of the building in the sections of most of the columns of the upper floors, namely the sections of most of the columns of the building from the fourth to the ninth floors, the stress values in the sections of the elements were far less than their threshold values. Such destruction is explained by the fact that bearing capacity of the columns of ground floor is exhausted due to minimal development of plastic deformations before destruction.

This example suggests that the possibility for considerable plastic deformations is not ensured before destruction upon designing of reinforced concrete wall-frame systems, considering valid regulations. This condition limits the ability of such designed system to resist considerable seismic loads exceeding design value established by valid regulations.

It is also impossible to increase the bearing capacity of these columns and the building in general by increasing the number of longitudinal reinforcement in the column since the development of significant plastic deformations and, accordingly, an increase in the bearing capacity of the columns is limited by the maximum value of concrete deformability under compression force.

It is not reasonable to increase in the bearing capacity of columns of lower stories with a high level of compression through longitudinal force due to an increase in the number of longitudinal reinforcement with a fixed value of the cross-sectional dimensions of the columns and the class of concrete. Simple increase in reinforcement percentage of longitudinal reinforcement in sections of the columns of the lower stories of multi-storey buildings, in which the level of longitudinal compressive forces is very high, leads to underutilization of the strength properties of reinforcement at the time of destruction of the columns. This is explained by the fact that tensions in sections of tensioned reinforcement fail to reach threshold values of tension under conditions that correspond to maximum compressibility of concrete in compressed area. In other words, there are no preconditions for the formation of plastic hinges and, accordingly, for the redistribution of forces from overloaded sections to light loaded sections. In such cases, brittle fracture occurs in the compressed zone of concrete with the loss of stability of compressed reinforcement.

It is well-known that the ability of the system, including frame buildings, to absorb seismic energy during destructive impacts depends on the degree of development of plastic deformations in the elements of the system before destruction provided that building will not lose general stability in the course of formation of plastic deformations. Therefore, the building should be designed in a way that allows the development considerable plastic deformations in system elements if seismic effect exceeds designed value stipulated by regulations. It is necessary to increase the ability of the building to absorb excessive seismic energy associated with the increase of the level of seismic impacts of its calculated value stipulated by regulations. The improvement in development of plastic deformations in system elements increases the ability of the system to absorb excessive seismic energy due to increase in the level of seismic impact against its design value.

Judging from the results of a numerical study of the 9-story frame building, system designed to meet the requirements of antiseismic construction standards when seismic impact level exceeds its estimated value, stipulated by the standards, is destroyed as a result of the destruction of the lower floor columns when minor inelastic deformations develop. Certain safety margin of the building was observed in comparison with its design values under such type of destruction however such safety margin was very small. In our case, designed building was able to withstand load that exceeds designed value stipulated by regulation only by $10 \%$. In this case, coefficient value showing the ability of the system to deform under loads, exceeding value of designed seismic loads until system destruction was only $K=171.3 / 126.8=1.35$. 
These values, namely, the value of destructive load and the value of the deformation factor of a 9-story wallframe building characterize the low energy intensity of the adopted system of 1 st variant building. Therefore, it is necessary to increase the ability of the system to absorb seismic energy. For this purpose, it is necessary to provide for certain measures for improvement of these system characteristics, which, in their turn, will have positive effect on improvement of dissipative properties of the system.

At the design stage, it is necessary to adopt such characteristics of the building structures that ensure high deformation factor $K$ before destruction or at the time of destruction.

In order to study this issue, we have considered the second and third variant of the 9-storey frame building under loads of a special combination, taking into account seismic effect with an intensity exceeding the calculated values stipulated by valid regulations.

As it was mentioned above, such dimensions of column cross section were adopted so that longitudinal reinforcement in columns fails doesn't exceed 3\%. At the same time, the condition of minimum reinforcement of columns conformed to design requirements of the SNiP RK [4]. The study of constructive system of the second variant showed that the destruction of this system also occurred as a result of the destruction of the columns of the lower floors. But for this system, the number of columns before the destruction amounted to a greater number in comparison with the first version. Figure 4 shows the "horizontal load - horizontal displacement" dependence of the second version of the building frame system.

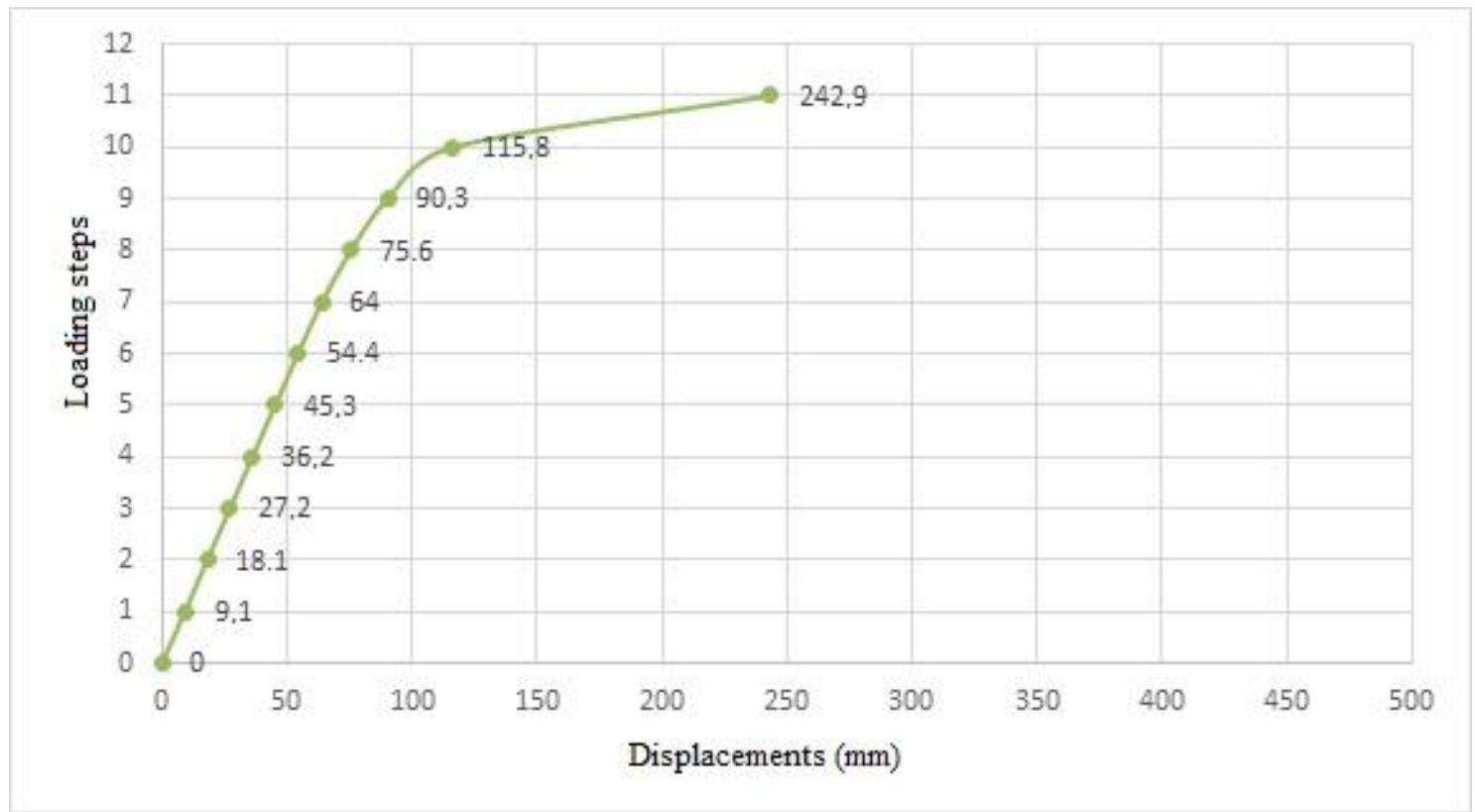

Figure 4. Dependence "horizontal load - horizontal displacement" for the second version of the building

An increase in the cross section of the columns from the first to the fourth floors from $45 \times 45 \mathrm{~cm}$ and $40 \times 40$ $\mathrm{cm}$ by $50 \times 50 \mathrm{~cm}$ allowed us to obtain a constructive system with a coefficient $K=2.1$. The excess of the destructive horizontal load over seismic load corresponding to the calculated value stipulated by regulations was $10 \%$.

In the third version of the frame structure, as noted above, the dimensions of the cross sections of the columns are adopted in such a way that the number of longitudinal reinforcement of the columns is adopted to be close to the minimum reinforcement of the columns in accordance with the requirements to antiseismic construction [4]. The results of the numerical study of the third version of the frame structure are shown in Figure 5 where the "horizontal load - horizontal displacement" dependence is shown under the effect of loads of a special combination considering the elastic-plastic properties of construction materials for the third variant of the building system. 


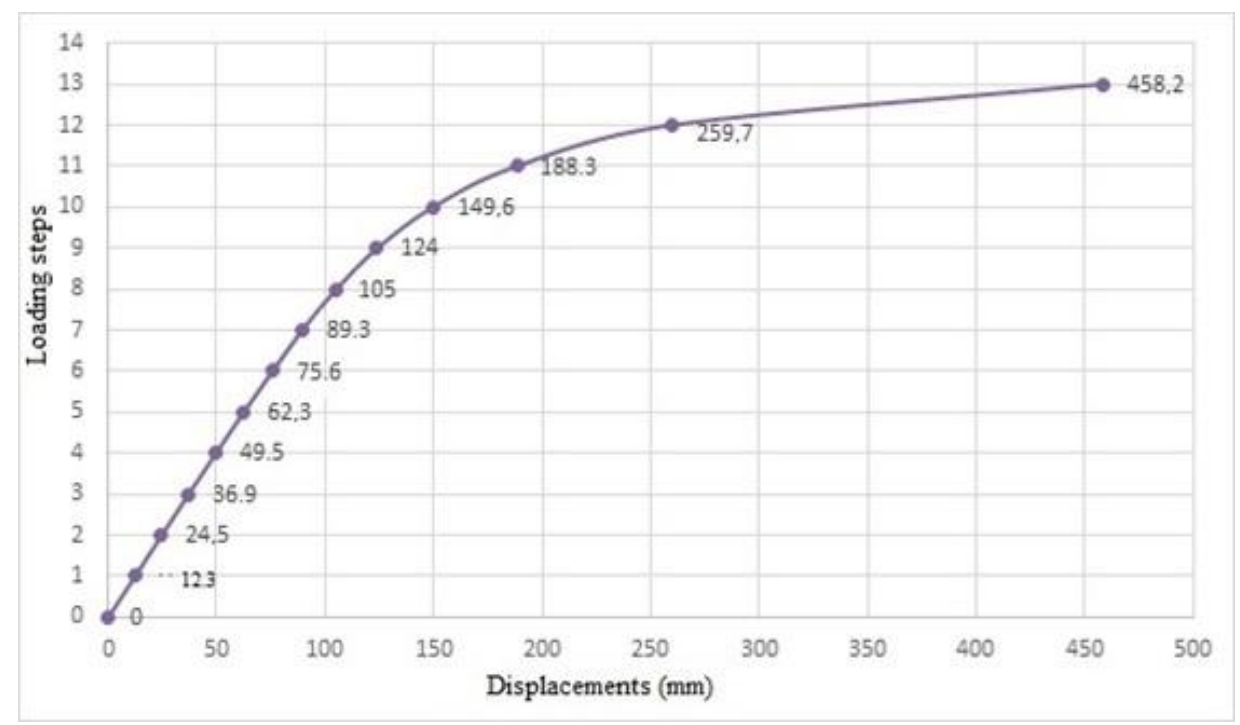

Figure 5. Dependence "horizontal load - horizontal displacement" for the third version of the building system

The study of behavior of the constructive system of the third variant showed that the destruction of this system also occurred due to destruction of the columns. However, the number of involved columns before the destruction was equal to approximately $80 \%$ of the total number of columns of building frame.

The results of the numerical study of the 9-story reinforced concrete frame building corresponding to the third version of the system show significantly better results compared to behavior of frames designed to meet the requirements of the SNiP RK [4]. For the considered version, we used higher safety margin of the building in comparison with its design value. This margin was equal to $30 \%$ in terms of load rate. In other words, the building of the third version withstood the load exceeding the calculated one established for by regulations by $30 \%$. The value of the coefficient that demonstrates deformability properties when the system is subject to loads exceeding the calculated values before destruction, was $K=3.1$.

The estimate of the system's bearing capacity under loads of special combination considering seismic effects was made according to method based on the principle of comparing external energy and internal forces. According to this method described in the work of I.L. Korchinskiy [3], certain amount of energy should be spent for destruction of elements. Moreover, it does not matter whether entire energy will be spent simultaneously or in separate portions for the " $n$ " number of loadings. According to this technique, the maximum seismic force $S_{\max }$, which this system can bear, considering elastic-plastic behavior of materials of constructions, is determined by the following formula:

$$
S_{\max }=\sqrt{S_{y}^{2}+\frac{k \cdot\left[E_{p l}\right]}{n}},
$$

where $E_{p l}$ is the inelastic energy absorption capacity of the system, i.e. the energy absorbed by the element in the process of vibration of the system;

$S_{y}$ is seismic force corresponding to the elastic operation of the system;

$k$ is rigidity of the system;

$n$ is a number of reloads during an earthquake.

As can be seen from this formula, the more the system has a plastic property, the greater is the load taken by the system under the effect of alternating dynamic load.

Figures 6-8 show the relative "load-displacement" dependencies for three variants of frame building with the formation of plastic deformations. 


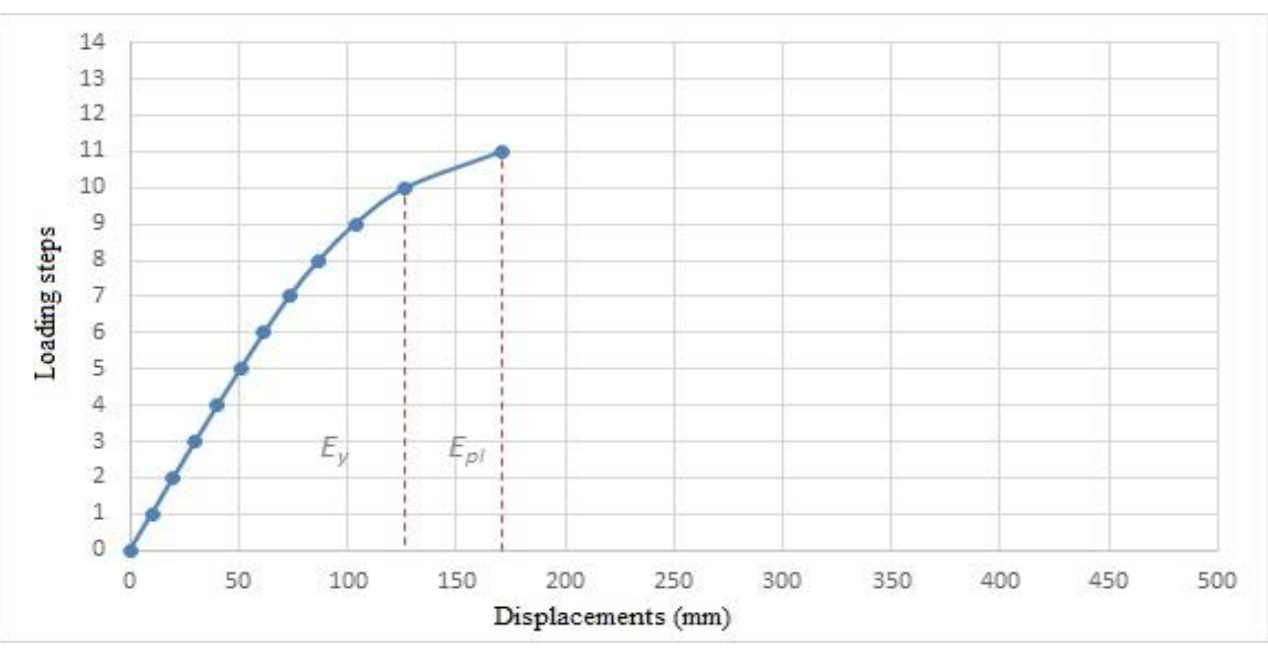

Figure 6. Comparative dependence "load-displacement" for the first variant of wall-frame building under loads of a special combination

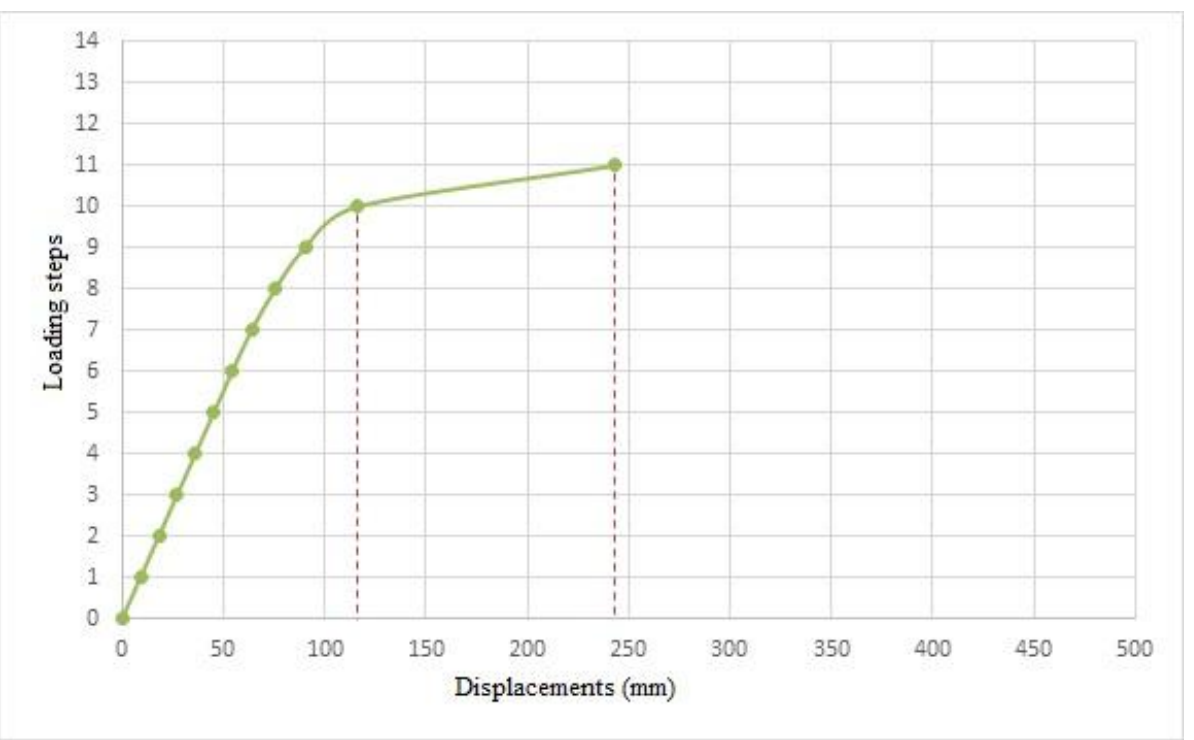

Figure 7. Comparative dependence "load-displacement" for the second variant of wall-frame building under loads of a special combination

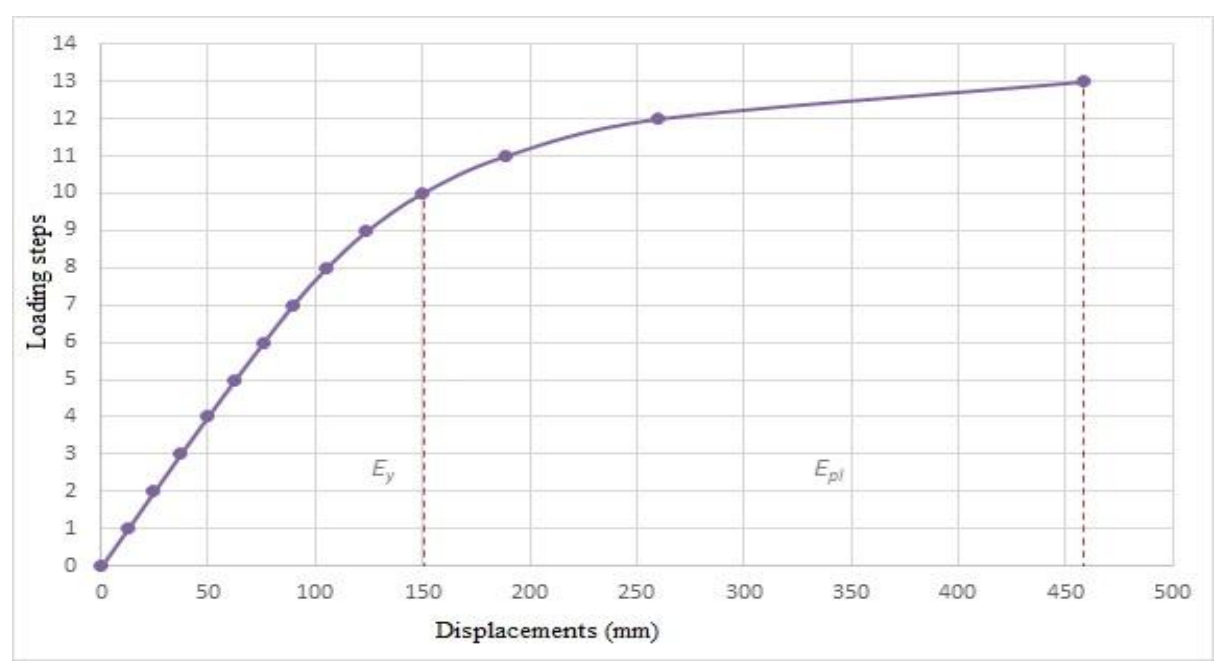

Figure 8. Comparative dependence "load-displacement" for the third variant of wall-frame building under the loads of a special combination 
The characteristics of each of the above systems describing their ability to resist the effects of loads of a particular combination, considering the seismic effects, when an earthquake exceeds the calculated value established by the standards, are shown in Table 1 .

Table 1. The results of a numerical study of the framework of the frame scheme on the effect of loads of a special combination

\begin{tabular}{lcccc}
\hline $\begin{array}{l}\text { Frame } \\
\text { variant } \\
\text { No. }\end{array}$ & $\begin{array}{c}\text { The maximum level } \\
\text { of compression of } \\
\text { columns of the lower } \\
\text { floors of frame } \\
\text { structure under } \\
\text { longitudinal force } \\
N_{\max } / R_{b} b h_{0}\end{array}$ & $\begin{array}{c}\text { The percentage of } \\
\text { longitudinal } \\
\text { reinforcement of } \\
\text { frame columns, } \\
\%\end{array}$ & $\begin{array}{c}\text { The ratio of destructive } \\
\text { horizontal load to the } \\
\text { calculated value of the } \\
\text { horizontal load simulating } \\
\text { seismic load } P_{u} / P_{y}\end{array}$ & $\begin{array}{c}\text { The value of the coefficient } \\
\text { showing the ability of the } \\
\text { system to deform when the } \\
\text { horizontal loads exceed the } \\
\text { calculated value established by } \\
\text { the standards } K\end{array}$ \\
\hline 1 & 2.12 & $0.8-6.0$ & 1.1 & 1.35 \\
\hline 3 & 1.47 & $0.8-3.0$ & 1.3 & 2.10 \\
\hline
\end{tabular}

Columns of buildings designed for seismic areas are symmetrically reinforced elements. The compression level for such elements can be characterized by the ratio of longitudinal compressive force $N$ to the value $R_{b} b h_{0}$. In this case, the relative height of the compressed zone of concrete $\xi$ will be less than the boundary height $\xi_{R}$. It is necessary to reduce compression level in order to increase the plastic properties of the system in general. To reduce compression level of the columns in order to increase the plastic properties of the system in general, it is necessary to increase the cross-sectional dimensions of the columns or improve concrete grade.

The obtained results allow the designer to create the conditions for formation of plastic hinges in the largest possible number of sections of the frame elements. This leads to the increase in the energy intensity of the frame, which is able to absorb the excess energy of the destructive earthquake. Moreover the proposed methodology for increasing the energy intensity of the frame makes it possible to evaluate this increase in numerical terms.

As mentioned earlier, in similar studies, calculations were also performed to increase the seismic resistance of multi-storey frame buildings taking into account physically non-linear behavior, mathematical modeling et al. was used [6-14]. But in the conducted studies for the design of buildings, the authors used generally accepted recommendations for calculations [4]. The authors of this article departed from the general rules, due to which they got a much better result - the strength of the building increased by $30 \%$.

Also in these articles [15-25], the authors conducted research on buildings at the construction stage or which were already subjected to an earthquake. This study allows to evaluate in advance, at the design stage of the building, the carrying capacity of the system in excess of the magnitude of the seismic loads of the design magnitude. The proposed methodology for increasing the energy consumption of the frame is unique; it has not been studied in earlier researches.

\section{Conclusions}

The results of the numerical study of the 9-story reinforced concrete frame building corresponding to the third version of the system show significantly better results compared to behavior of frames. For the considered version, we used higher safety margin of the building in comparison with its design value. This margin was equal to $30 \%$ in terms of load rate. The value of the coefficient that demonstrates deformability properties when the system is subject to loads exceeding the calculated values before destruction, was $\mathrm{K}=3.1$.

The results of this study have shown that the use of nearly maximum quantity reinforcement in the columns of the frame of multi-storey wall-frame buildings, which meets the requirements of the standards, does not 
contribute to the improvement of plastic properties of the system in general. In other words, it is impossible to reduce the level of seismic loads by simply setting the level of reduction through the use of above-mentioned coefficients to the value of seismic loads, based on assumed elastic behavior of the system. It is necessary to check the possibility for development of plastic deformations of the system under seismic loads.

The results of this numerical study gives the designer an opportunity to verify the degree of development of inelastic deformations of the system under seismic impact at design stage by taking appropriate measures in designing seismic-proof buildings and structures. Thus, developed recommendations based of the obtained research results make it possible to estimate in advance, at the design stage, the bearing capacity of the system when seismic load exceeds the design value.

Considering above-mentioned facts, the major measure for increasing load absorption capacity of the system is designing of columns with reduced axial compression level. This can be achieved by increasing the crosssectional dimensions of the columns or improvement of concrete resistance to axial compression, while observing the requirements to minimum allowable longitudinal reinforcement. The implementation of these measures allows designing of the system suitable for development of significant plastic deformations under seismic loads that exceed design values.

Based on the analysis of the results of numerical study of the behavior of multi-storey reinforced concrete frame building under of loads of special combination considering the seismic impact, the following recommendations are proposed for estimating the bearing capacity margin of considered systems designed for seismic areas in case of a destructive earthquake:

- Frame elements should be adopted (dimensions of column cross section, percentage of longitudinal and transversal reinforcement, concrete and reinforcement grade) based on the calculation of wallframe building and requirements to current antiseismic construction norms. Based on adopted characteristics of the frame, it is necessary to check the deformability of the building using both elastic and elastic-plastic calculation and considering the real properties of materials of the structures calculated by software systems;

- It is necessary to calculate the resistance of this system to loads of special combination, considering seismic effect and nonlinear behavior of system elements until complete destruction. Seismic load should be simulated by horizontal load affecting system masses. The direction of horizontal seismic load should correspond to the first natural mode of the building and its values should be adopted, considering higher mode of vibrations.

- It is necessary to build a diagram 'Load-displacement' until complete destruction for the system designed based on requirements of valid antiseismic construction regulations. For this purpose, it is necessary to carry out calculations based on elastic-plastic characteristics of structure materials.

- It is necessary to determine bearing capacity margin based on energy absorption capacity of the system, considering characteristics that determine plastic properties of the system, i.e. coefficient $\mathrm{K}$ that indicates the ability of the system to resist loads that exceed calculated value;

- In case of minimal bearing capacity margin of the system, it is recommended to carry out calculations for improvement of plastic properties of the system. Characteristics of the elements of wall-frame building should be changed in such way so that dimensions of column cross section correspond to percentage of longitudinal reinforcement within $0.8 \%-3 \%$ of cross-section area of columns;

- Then it is necessary to carry out calculations in above-mentioned sequence to determine bearing capacity margin of the system to ensure maximum energy absorption capacity.

Major measure that allows the increase in energy absorption capacity at the stage of designing of wall-frame buildings is the reduction of the level of longitudinal forces in cross sections of columns by increasing the cross-sectional dimensions of the columns or improvement of concrete grade. The results of this work allow designers to create the required energy intensity of the frame of multi-storey buildings that can absorb the excess energy of destructive earthquake at design stage. 
The results of our work can be summarized as follows:

1. Favorable conditions for development of plastic hinges in the vertical elements of the reinforced concrete frame structure are disclosed.

2. A method for estimating the energy intensity of a reinforced concrete frame structure of multi-storey buildings was developed and tested in a numerical experiment.

3. Recommendations for improving the energy intensity of the reinforced concrete frame structure for destructive earthquake are proposed.

Our study allowed creating systems capable of absorbing the excess energy of destructive earthquakes at the design stage.

\section{References}

[1] N.N. Belov, O.V. Kabantsev, D.G. Kopanitsa and N.T. Yugov, Computational-Experimental Method for Analyzing the Dynamic Strength of Elements of Reinforced Concrete Structures, Tomsk: STT, 2008.

[2] S.V. Zhidkova and V.I. Mayorov, "Engineering Analysis of the Effects of Earthquakes", Earthquake Resistant Construction. Building Safety, no. 2, pp. 51-53, 2008.

[3] I.L. Korchinsky, Earthquake resistant building construction, Moscow: Vysshaya shkola, 1971.

[4] SNiP RK 2.03-30-2006. Construction in Seismic Areas. Design Standards. Available at: https://online.zakon.kz/Document/?doc id=30086309\#pos=1;16 (accessed 28/09/2019).

[5] SNiP II-7-81. Construction in Seismic Areas. Available at: http://www.gostrf.com/normadata/1/4294854/4294854805.pdf (accessed 28/09/2019).

[6] S.V. Bulushev, G.A. Dzhinchvelashvili and A.V. Kolesnikov, "Nonlinear static analysis method for seismic resistance of buildings and structures", Earthquake Resistant Construction. Building Safety, no. 5, pp. 39-47, 2016.

[7] G.A. Dzhinchvelashvili and A.V. Kolesnikov, "Calculation of Frame Buildings On Seismic Effects, Taking into Account the Development of Inelastic Deformations", Bulletin SIC Construction, no. 1, pp. 194-200, 2009.

[8] I.T. Mirsayapov and D.M. Nurieva, "Calculation of Multi-Storey Frame Buildings on Seismic Effects, Taking into Account the Physically Nonlinear Behavior", Earthquake Resistant Construction. Building Safety, no. 1, pp. 7-9, 2003.

[9] O.V. Mkrtychev and G.A. Dzhinchvelashvili, Problems of Accounting for Nonlinearities in the Theory of Seismic Resistance (Hypotheses and Delusions), Moscow: MGSU, 2012.

[10] O.V. Mkrtychev and G.A. Dzhinchvelashvili, "Evaluation of the Operation of Buildings and Structures Beyond the Elastic Limits During Seismic Effects", in. S. Lutomirski (Ed.), XXI Russian-Slovak-Polish Seminar "Theoretical Foundation of Civil Engineering", Warszawa: Politechnika Warszawska, pp. 177186, 2012.

[11] S.V. Polyakov and V.I. Oizerman, "Comparison of domestic and foreign design standards of buildings for construction in seismic areas", Construction and architecture. Series 8. Building structures: Survey information, no. 7, pp. 1-63, 1986.

[12] E.H.S. Symbort, "The Method of Selecting the Coefficient of Reduction of Seismic Loads K1 at a Given Level of Plasticity Coefficient", Engineering and Construction Journal, vol. 27, no. 1, pp. 44-52, 2012.

[13] W.Y. Kam, S. Pampanin, R. Dhakal, H.P. Gavin and C. Roeder, "Seismic Performance of Reinforced Concrete Buildings in the September 2010 Darfield (Canterbury) Earthquakes", Bulletin of the New Zealand Society for Earthquake Engineering, vol. 43, no. 4, pp. 340-350, 2010. 
[14] V.G. Dmitriev, "Mathematical Modeling of Non-Linear Deformation Processes of Frame-Type Building Structures Under Seismic Effects", International Journal for Computational Civil and Structural Engineering, vol. 8, no. 2, pp. 13-29, 2012.

[15] V. Dmitriev and A. Roffe, Study How Viscoelastic Damper Parameters Impact Deformation and LoadBearing Capacity of Frame-Type Reinforced Concrete Structures Under Seismic Loads", International Journal for Computational Civil and Structural Engineering, vol. 11, no. 1, pp. 104-114, 2015.

[16] S. Ray-Chaudhuri T.C. Hutchinson, "Effect of Nonlinearity of Frame Buildings on Peak Horizontal Floor Acceleration”, Journal of Earthquake Engineering, vol. 15, no. 1, pp. 124-142, 2011.

[17] S.R. Uma, S. Pampanin and C. Christopoulos, "Development of Probabilistic Framework for Performance-Based Seismic Assessment of Structures Considering Residual Deformations", Journal of Earthquake Engineering, vol. 14, no. 7, pp. 1092-1111, 2010.

[18] S. Pampanin, C. Christopoulos and M.J.N. Priestley, "Performance-based seismic response of frame structures including residual deformations part II: multi-degree of freedom systems", Journal of Earthquake Engineering, vol. 7, no. 1, pp. 119-147, 2003.

[19] L. Ye, X. Lu and Y. Li, "Design Objectives and Collapse Prevention for Building Structures in MegaEarthquake", Earthquake Engineering and Engineering Vibration, vol. 9, no. 2, pp. 189-199, 2010.

[20] M. Mosoarca, "Failure Analysis of RC Shear Walls with Staggered Openings Under Seismic Loads", Engineering Failure Analysis, no. 41, pp. 48-64, 2014.

[21] S.B. Smirnov, S.V. Romanenko, Yu.V. Shefer and B.K. Orozaliyev, "The Study of the Vibrational Model of Seismic Destruction of Buildings", Bulletin of the Kyrgyz-Russian Slavic University, vol. 1, no. 15 , pp. 127-130, 2015.

[22] A.V. Sosnin, "On the Algorithm for Specifying the Coefficient of Allowable Damage K1 Along the Bearing Capacity Curve for Estimating the Seismic Resistance of Reinforced Concrete Frame Buildings of Mass Construction", Housing Construction, no. 1-2, p. 60, 2017.

[23] A.V. Sosnin, "On the Issue of Accounting Dissipative Properties of Multi-Storey Reinforced Concrete Frame Buildings of Mass Construction in the Evaluation of Their Seismic Resistance", Modern Science and Innovation, no. 17, pp. 114-131, 2017.

[24] A.Kh. Manukyants, "Evaluation of Design Solutions for Multi-Storey Frame Building", Works of SKGMI (GTU), no. 23, pp. 163-165, 2016.

[25] J. Pejovic, N. Serdar and R. Pejovic, "Performance-based" Seismic Methodology and Its Application in Seismic Design of Reinforced Concrete Structures", Construction of Unique Buildings and Structures, no. 5(32), pp. 75-83, 2015.

[26] T.N. Tjhin, M.A. Aschheim and J.W. Wallace, "Yield Displacement-Based Seismic Design of RC Wall Buildings”, Engineering Structures, vol. 29, no. 11, pp. 2946-2959, 2007.

[27] P. Haldar, Y. Singh D.K. Paul, "Identification of Seismic Failure Modes of URM Infilled RC Frame Buildings", Engineering Failure Analysis, no. 33, pp. 97-118, 2013.

[28] L.H. Han, W. Li and Y.F. Yang, "Behaviour of Concrete-Filled Steel Tubular Frame to RC Shear Wall High-Rise Mixed Structures”, Journal of Constructional Steel Research, vol. 65, no. 5, pp. 1249-1260, 2009. Seismic

[29] S.H. Jeong, A.M. Mwafy and A.S. Elnashai, "Probabilistic Seismic Performance Assessment of CodeCompliant Multi-Story RC Buildings”, Engineering Structures, no. 34, pp. 527-537, 2012.

[30] European Committee for Standardisation. (1990-1999). EN Eurocode Parts. Available at: https://eurocodes.jrc.ec.europa.eu/showpage.php?id=13 (accessed 28/09/2019). 
[31] B.A. Antufiev, O.V. Egorova, A.A. Orekhov and E.L. Kuznetsova, "Dynamics of Thin-Walled Structure with High Elongation Ratio and Discrete Elastic Supports on the Rigid Surface under Moving Loads", Periodico Tche Quimica, vol. 15, no. 1, pp. 464-470, 2018.

[32] A.S. Kurbatov, A.A. Orekhov and L.N. Rabinskiy, "Solution of the Problem of Thermal Stability of a Thin-Walled Structure under Non-Stationary Thermal Action Arising in the Process of Creating Articles by the Method of Selective Laser Sintering", Periodico Tche Quimica, vol. 15, no. 1, pp. 441447, 2018.

[33] I.V. Kudryavtsev, E.S. Novikov, O.I. Rabetskaya, A.E. Mityaev, V.G. Demin, "Inertial Bending of a Thin-Walled Waveguide with Rectangular Cross-Section: Bending of Lateral Wall in its Plane", Periodico Tche Quimica, vol. 15, no. 1, pp. 41-54, 2018. 